\title{
COMPLEXIDADES PARA A APLICAÇÃO DOS ASPECTOS NORMATIVOS PARA A GESTÃO DE RECURSOS HÍDRICOS NO BRASIL
}

\author{
Frank Pavan de Souza ${ }^{1 *} \&$ Monica Pertel ${ }^{2}$
}

\begin{abstract}
RESUMO
SOUZA, F.P.; PERTEL, M. Complexidades para a aplicação dos aspectos normativos para a gestão de recursos hídricos no Brasil. Perspectivas Online: Exatas \& Engenharia, v.10 , n.27, p.70 - 82, 2020.

Nos últimos tempos, tem se percebido cada vez mais o consumo de água em processos produtivos e também nas áreas de saneamento. Seja para o consumo humano ou para as atividades industriais, a água é um recurso natural de extrema importância para manter a vida no planeta. O uso exacerbado desse recurso pode torná-lo escasso. Neste sentido, o objetivo dessa pesquisa foi analisar as complexidades para a aplicação dos aspectos normativos para a gestão de recursos hídricos no Brasil. Para o desenvolvimento da pesquisa foram verificadas as principais legislações federais associadas à gestão de recursos

método adotado foi o dedutivo e a pesquisa classifica-se como bibliográfica. Por meio de plataformas científicas digitais, livros, teses, dissertações, foi realizado um levantamento de informações técnicas e jurídicas relacionadas à gestão de recursos hídricos. Ao final, pôde-se concluir que no Brasil, existe um emaranhado de leis e normas aplicáveis a gestão dos recursos hídricos. Tais aspectos jurídicos, se aplicados de forma coesa e coletiva, podem contribuir com a gestão, melhor distribuição e manutenção da água em quantidade e qualidade disponíveis para todos os usuários.
\end{abstract} hídricos no Brasil (Lei 9.433/1997 e Código de Águas de 1934), bem como autores especialistas no tema abordado. O

Palavras-chave: Gestão; Recursos Hídricos; Água. 


\begin{abstract}
Nowadays, water consumption has been increasingly perceived in production processes and also in the sanitation areas. Whether for human consumption or for industrial activities, water is a natural resource of extreme importance for maintaining life on the planet. Exaggerated use of this feature can make it scarce. In this sense, the objective of this research was to analyze the complexities for the application of the normative aspects for the management of water resources in Brazil. The main federal legislation associated with water resources management in Brazil (Law 9.433 / 1997 and the Water Code of

1934) was verified for the development of the research, as well as authors specializing in the subject. The method adopted was the deductive and the research was classified as bibliographical. Through digital scientific platforms, a survey of technical and legal information related to the management of water resources was carried out. At the end, it can be concluded that in Brazil, there is a tangle of laws and norms applicable to the management of water resources. Such legal aspects, if applied in a cohesive and collective way, can contribute to the management, better distribution and maintenance of water in quantity and quality available to all users.
\end{abstract}

Keywords: Management; Water resources; Water.

\footnotetext{
${ }^{1}$ Institutos Superiores de Ensino do CENSA - ISECENSA - Rua Salvador Correa, 139, Centro, Campos dos Goytacazes, RJ, CEP: 28035-310, Brasil;

${ }^{2}$ Universidade Federal do Estado do Rio de Janeiro - UFRJ - Av. Pedro Calmon, 550, Cidade Universitária, Rio de Janeiro, RJ, CEP: 21941-901, Brasil.

(*) e-mail: frankpavan@gmail.com

Data de recebimento: 19/06/2019. Aceito para publicação: 07/02/2020.
}

Persp. Online: exatas \& eng., Campos dos Goytacazes, 27 (10) 70 - 82 - 2020

seer.perspectivasonline.com.br 


\section{INTRODUÇÃO}

A água representa um insumo fundamental para o sustento do planeta. De fato, os seres vivos não possuem autossuficiência em seus organismos que os condicionem a viver sem a água. Do ponto de vista social, a interferência da água traz alterações significantes nos ambientes, tendo em vista que pode ser um instrumento de movimentação ou de transformação na economia.

De acordo com Pavan et al. (2016) a importância da água e a preocupação com sua escassez para as gerações futuras expõem complexidades existentes relacionadas à má utilização da água: o processo de urbanização desenfreada e a geração de resíduos com descarte inapropriado contaminando os ecossistemas aquáticos.

Segundo estudos da Fundação das Nações Unidas para Alimentação e Agricultura (FAO), foi verificado que o consumo da água no planeta está dividido da seguinte forma: $70 \%$ para irrigação, $20 \%$ para atividades industriais e $10 \%$ para usos urbanos (ONU, 2014)

De acordo com Caponera (2012), a importância da água, em todos os aspectos das atividades humanas, é bem conhecida, já que sua disponibilidade representa uma condição básica para a sobrevivência dos seres humanos, dos animais e das plantas. É por meio da combinação de água com um ou mais recursos naturais básicos que os outros recursos "secundários" são disponibilizados. Combinada com a terra fornece florestas, que são, por sua vez, indispensáveis para sustentar a vida humana e animal.

Quanto ao aspecto social, o recurso hídrico bem gerenciado pode transformar ambientes que podem se tornar áreas próprias e, ao mesmo tempo, impróprias para viver, tendo em vista a forma como é gerenciada. São justamente estes fatores que fazem com que a água se torne um recurso passível de conflito, ou seja, desde o momento em que passou a se tornar um recurso, a sociedade discute as suas relações.

O Brasil dispõe de um ordenamento jurídico voltado à proteção dos recursos hídricos, porém estas leis encontram-se esparsas, não alcançando na sua individualidade os objetivos propostos pelos legisladores, fato que pode acarretar conflito nos procedimentos de gestão.

Este fato pode ser verificado na Política Nacional de Recursos Hídricos, que apesar de ter sido editada com a finalidade de gerenciar os recursos hídricos no país, em algumas situações, vai de encontro aos outros instrumentos legais existentes ou os contradiz..

A existência de dispositivos legais sobre a proteção e a gestão de recursos hídricos no País não garante o cumprimento efetivo deles. De fato, os aspectos legais tornam-se referências para a execução de procedimentos padronizados e, se elaborados de forma técnica, podem contribuir com o controle e monitoramento do uso das águas. O trabalho se justifica pelo fato de haver a necessidade de se sistematizar os instrumentos legais de gestão de recursos hídricos no Brasil de forma que essas leis não se sobreponham, mas se complementem.

Neste sentido, o objetivo desta pesquisa foi verificar as complexidades para a aplicação dos aspectos normativos para a gestão de recursos hídricos no Brasil, com vistas a uma possível integração do ordenamento jurídico ambiental.

Persp. Online: exatas \& eng., Campos dos Goytacazes, 27 (10) 70 - 82 - 2020

seer.perspectivasonline.com.br 


\section{METODOLOGIA}

A pesquisa classifica-se como bibliográfica tendo em vista que, segundo Lima e Mioto (2007), implica um conjunto ordenado de procedimentos de busca por soluções, atento ao objeto de estudo e que, por isso, não pode ser aleatório.

Para Bervian (1983), a pesquisa bibliográfica explica um problema a partir de referenciais teóricos publicados em documentos. Pode ser realizada independentemente ou como parte da pesquisa descritiva experimental. Ambos os casos buscam conhecer e analisar as contribuições culturais ou científicas do passado, existentes sobre um determinado assunto, tema ou problema.

O método adotado foi o dedutivo e, de acordo com Mezzaroba (2014), parte de argumentos gerais para argumentos particulares, ou seja, inicialmente são apresentados os argumentos que se consideram verdadeiros e inquestionáveis para, em seguida, chegar a conclusões formais uma vez que elas ficam restritas única e exclusivamente à lógica das premissas estabelecidas.

Para identificação das principais legislações federais associadas à gestão de recursos hídricos foi realizado um levantamento de informações técnicas e jurídicas junto aos órgãos de fiscalização e controle, bem como sites de órgãos oficiais como IBAMA e INEA. Tendo em vista que os aspectos legais ambientais no Brasil possuem, em sua amplitude, vasta discussão, optou-se por utilizar a Constituição Federal de 1988, o Código de Águas de 1934 e Política Nacional de Recursos Hídricos de 1997 como referência dos aspectos legais, para a pesquisa e, ainda, autores que discutem e argumentam sobre a gestão de recursos hídricos no País.

\section{RESULTADOS E DISCUSSÃO}

Tendo em vista que o uso das águas no Brasil era estabelecido por aspectos legais obsoletos, em desacordo com as necessidades e os interesses da coletividade nacional; que esse estado de coisas precisava ser modificado, para se adotar legislação adequada que permitisse, de acordo com a tendência da época, o controle e o incentivo do aproveitamento industrial das águas, em particular as medidas que facilitassem e garantissem $o$ aproveitamento racional da energia hidráulica; e, considerando que, com a reforma pela qual haviam passado os serviços afetos ao Ministério da Agricultura, o Governo estava aparelhado, por seus órgãos competentes, a ministrar assistência técnica e material indispensáveis à consecução daqueles objetivos, o Governo Provisório decretou o Código de Águas, em 10 de julho de 1934, retificado em 27 de julho de 1934 (POMPEU, 2010).

O início da gestão de recursos hídricos no Brasil se deu com a publicação desse Código, já que, naquela época, as águas eram consideradas como recurso natural renovável, fato que levou ao incentivo do desenvolvimento industrial e agrícola no país, abordando principalmente a produção de energia elétrica. O Código faz menção às águas públicas, àquelas que podem ser de uso comum ou dominicais, e ainda, dispõe sobre as águas particulares de uso comum.

É importante ressaltar que as águas públicas de uso comum ou patrimoniais, dos Estados ou dos Municípios, bem como as águas comuns e as particulares, poderiam ser desapropriadas por necessidade ou por utilidade pública, deixando o legislador a responsabilidade da desapropriação pela União em todas as situações, as águas dos

Persp. Online: exatas \& eng., Campos dos Goytacazes, 27 (10) 70 - 82 - 2020

seer.perspectivasonline.com.br 
municípios e as particulares sob competência do Estado e as particulares exclusivamente sob responsabilidade do Município.

É possível verificar que o Código de Águas destaca um capítulo para as águas comuns e assegura o uso gratuito de qualquer corrente ou nascente de águas, para as primeiras necessidades da vida, quando houver caminho público que as torne acessíveis. Define que caso não haja caminho, os proprietários marginais não podem impedir que seus vizinhos se aproveitem das mesmas para aquele fim, contanto que sejam indenizados do prejuízo que vierem a sofrer com o trânsito pelos seus prédios, deixando claro que a servidão só se dará verificando-se que os ditos vizinhos não podem obter água de outra parte, sem grande incômodo ou dificuldade.

O Código conceitua as águas particulares como aquelas situadas em terrenos que também o sejam, quando elas não estiverem classificadas entre as águas comuns de todos, as águas públicas ou as águas comuns. Quanto às águas de dominialidade da União, refere-se às águas marítimas as situadas no Território do Acre ou em qualquer outro território que a União venha a adquirir, enquanto o mesmo não se constituir em Estado ou for incorporado a algum Estado. O Código define como pertencente à União as águas que serviam de limites da República com as nações vizinhas ou se estendiam ao território estrangeiro. A dominialidade se estende às águas quando situadas na zona de 100 quilômetros contígua aos limites da República com estas nações e finaliza mencionando que as águas que serviam de limites entre dois ou mais Estados, bem como as que percorriam parte dos territórios de dois ou mais Estados, estavam sob domínio da União.

O Código das Águas foi o marco histórico regulador dos procedimentos de uso e controle da água no Brasil. Com o olhar voltado para a história das águas, é possível perceber que este instrumento legal foi elaborado com vistas a estabelecer um regime jurídico de águas no Brasil, tendo como pano de fundo a classificação e utilização da água, bem como o aproveitamento hidráulico, fixando as respectivas limitações administrativas de interesse público.

Braga (2009) ministra que o Código de Águas é considerado mundialmente como uma das mais completas leis de águas já produzidas. Os princípios nele constantes ainda são invocados em diversos países como modelos a serem seguidos, mesmo em legislações modernas. Veja-se, por exemplo, que o princípio do poluidor-pagador, introduzido na Europa como novidade na década de 70, está previsto em seus arts. 111 e 112.

No mesmo ano (1934) foi publicada a Constituição Federal com algumas inovações e, em se tratando de água, utilizou o Código das Águas como parâmetro para estabelecer funções, critérios e para discutir as demandas referentes à água no país.

Levando-se em consideração as prerrogativas apresentadas pelo Código das Águas, percebe-se que seus instrumentos normativos estão direcionados para "águas" de forma sistêmica. Verifica-se que o Código foi elaborado com vistas à ampliação do controle dos "usos" e para facilitar a fiscalização, já que antes do mesmo não havia um instrumento legal capaz de abranger "isoladamente" os conceitos de gestão das águas no País.

Valer ressaltar que, passados dez anos da publicação da atual Constituição Federal da República do Brasil, foi inserida no contexto legal nacional a Lei de Crimes Ambientais LCA (Lei 9.605/1998), que prevê em seu Artigo $3^{\circ}$ a responsabilização penal, administrativa e civil aplicadas cumulativamente ou independentes ao mesmo fato ou crime, e assim dispõe:

Persp. Online: exatas \& eng., Campos dos Goytacazes, 27 (10) 70 - 82 - 2020

seer.perspectivasonline.com.br 
Artigo 225, $\S 3^{\circ}$ - As condutas e atividades lesivas ao meio ambiente sujeitarão os infratores, pessoas físicas ou jurídicas, a sanções penais e administrativas, independentemente da obrigação de reparar os danos causados.

Artigo $3^{\circ}$ - As pessoas jurídicas serão responsabilizadas administrativamente, civil e penalmente conforme o disposto nesta Lei, os casos em que a infração seja cometida por decisão de seu representante legal ou contratual, ou de seu órgão colegiado, no interesse ou benefício da sua entidade.

Artigo $3^{\circ}$, parágrafo único - A responsabilidade das pessoas jurídicas não exclui a das pessoas físicas, autoras, coautoras ou partícipes do mesmo fato.

Seguindo a lição Constitucional vigente, a Lei de Crimes Ambientais também criminalizou a poluição hídrica, ao teor do que dispõe o Artigo 54, § $2^{\circ}$ III, ou seja:

Artigo 54 - Causar poluição de qualquer natureza em níveis tais que resultem ou possam resultar em danos à saúde humana, ou que provoquem a mortandade de animais ou a destruição significativa da flora.

$\S 2^{\circ}$ Se o crime:

III - causar poluição hídrica que torne necessária a interrupção do abastecimento público de água de uma comunidade;

Pena - reclusão, de um a cinco anos.

Como dito anteriormente, o princípio do poluidor-pagador, que objetiva impor ao poluidor e predador a obrigação de recuperar e/ou indenizar os danos causados por sua atividade ao Meio Ambiente teve origem na legislação brasileira com o Código de Águas, ao teor dos Artigos 111 e 112. Todavia, este princípio restou inócuo na legislação brasileira até sua adoção pela Política Nacional do Meio Ambiente, ou seja, Lei 6.938/81, que o prescreve em seu Artigo $4^{\circ}$, VII.

Neste entendimento, faz-se necessária a cobrança, tanto pelo aspecto financeiro, proporcionando investimentos no setor, quanto pela conscientização do valor econômico dos recursos naturais, difundindo a imprescindibilidade do uso racional.

Ainda assim, este elemento jurídico faz parte do marco histórico do início da gestão das águas em nosso território, pelas considerações e articulações que foram geradas a partir do mesmo.

De todos os problemas ambientais já vivenciados atualmente, o dos recursos naturais merece maior atenção por não existirem alternativas que o substitua. A água é um bem vital para sobrevivência de todos os seres vivos e para o ecossistema terrestre. No entanto, a gestão de recursos hídricos deve ser incorporada pelo poder público e pela sociedade, para que todos os bens naturais, e não somente a água, seja preservada para presentes e futuras gerações. $\mathrm{O}$ uso e a conservação da água são resultados da história humana, com seu legado de

Persp. Online: exatas \& eng., Campos dos Goytacazes, 27 (10) 70 - 82 - 2020

seer.perspectivasonline.com.br 
conhecimento, práticas, instrumentos e organizações com base nos quais nenhum indivíduo pode reivindicar direitos de propriedade (PETRELLA, 2002).

O Código de Águas de 10 de Julho de 1934 foi o primeiro instrumento legal a assegurar o uso dos recursos hídricos. Este decreto tinha como principal objetivo controlar e incentivar o aproveitamento industrial das águas. Durante praticamente sessenta anos, o uso das águas no território nacional ficou sob a tutela deste decreto. Entretanto, a partir da década de 90, o Brasil passou a elaborar uma série de instrumentos de gestão das águas, em nível federal, estadual e municipal (ADAM, 2008).

Em 1997 foi instituída a Política Nacional dos Recursos Hídricos, com a publicação da Lei Federal $n^{\circ}$ 9.433, estabelecendo como objetivo central o gerenciamento dos recursos hídricos, visto que os problemas ocasionados pelo uso da água já eram vivenciados por muitos países e por algumas populações brasileiras.

Este mecanismo legal busca elaborar estruturas institucionais e delegar funções específicas para gestão de recursos hídricos nas bacias hidrográficas, tendo em vista a necessidade da aplicação da gestão compartilhada e levando em consideração questões como disponibilidade hídrica, cobrança, tipos de usos, outorgas e alocação de dados num sistema modular de informações que abrange todo o país.

Nesse sentido, o conjunto de diretrizes sobre as quais se apoia todo o desenvolvimento desta nova visão da administração da água é prescrito pelo Artigo $1^{\circ}$ da Lei 9433/97 que consagra os seguintes preceitos como fundamentos da Política Nacional de Recursos Hídricos - PNRH (BRASIL, 1997).

Ao definir a água como bem de domínio público, o legislador deixou claro que esta pertence a todos. Sendo assim, sempre haverá necessidade de se tornarem públicas as ações (administrativas, cíveis, criminais e ambientais) tanto referentes à administração pública como do setor privado, tendo como base o princípio da publicidade dos atos processuais.

No antigo Código de Águas (Decreto 24.643/1934) havia previsão da existência de águas particulares. Entretanto, com a publicação da PNRH, essa classificação torna-se extinta, tendo em vista que foi estabelecido o domínio público da água, ficando o Poder Público apenas com o dever de gerenciar as ações em função da coletividade.

Ademais, se o legislador declara a água como um "bem", automaticamente torna-a um patrimônio que, sendo público, deve ser mantido, administrado, fiscalizado e gerenciado por órgãos da administração pública e pela sociedade. Como patrimônio que deve ser mantido, controlado e gerenciado, a água, considerada recurso natural limitado, torna-se um bem dotado de valor econômico.

Em face de uma possível escassez comprovada pela ciência, e em algumas regiões pelas condições sanitárias e ambientais em que vivem, já é do consenso internacional que a água possui valor econômico. No entendimento de Granziera (2006), os recursos hídricos são bens de valor, à medida que há interesse sobre ele. Tornando-se escasso, esse valor passa a ter caráter econômico.

Neste sentido, verifica-se que Organização das Nações Unidas ONU (1992) declarou que "a água não é uma doação gratuita da natureza; ela tem um valor econômico: precisa-se

Persp. Online: exatas \& eng., Campos dos Goytacazes, 27 (10) 70 - 82 - 2020

seer.perspectivasonline.com.br 
saber que ela é, algumas vezes, rara e dispendiosa e que pode muito bem escassear em qualquer região do mundo".

Para Lemos (2003), embora a água seja um recurso renovável, sua quantidade é limitada: menos de 200 mil quilômetros cúbicos estão disponíveis em rios e lagos. Esta quantidade era suficiente em 1900, quando cerca de 2 bilhões de habitantes viviam no planeta. Agora, com uma população que alcança 7 bilhões, e como a água não está distribuída de forma proporcional à população existente, a quantidade de água disponível já chega perto do limite: $40 \%$ da população mundial já sofre de escassez de água.

A ideia de disponibilidade em abundância fez com que os seres humanos utilizassem os recursos hídricos sem o devido controle, e tal atitude trouxe para o legislador responsabilidade de garantir aos seres humanos prioritariamente o uso dos recursos hídricos. De acordo com Petrella (2002), caso o atual ritmo de exploração dos recursos hídricos continue inalterado, estima-se que em 2025 a metade da população mundial não terá acesso à água potável. É com este pensamento que o legislador fundamenta a importância da gestão dos recursos hídricos levando em consideração o uso múltiplo das águas.

As intervenções humanas propiciam um agravamento na escassez hídrica para o consumo, por meio do desenvolvimento industrial, crescimento urbano desordenado, entre outros problemas que agravam ainda mais a qualidade dos recursos hídricos (ZILBERMAN, 2004). O problema de escassez de água pode ser definido de duas maneiras: má distribuição, ocasionada pela própria natureza, denominando-se escassez física. E má gestão, que é a incapacidade de aquisição da água, devido aos altos custos, sendo identificado como escassez econômica. Regiões da África e Oriente Médio já sofrem, gravemente, com a falta deste bem. Contudo, mesmo nas regiões privilegiadas, as fontes de água e os centros consumidores podem ser distantes, dificultando na gestão (LIMA, 2005).

O Brasil é considerado um país rico em água, já que conta com $12 \%$ da água doce do mundo, porém a mesma não se encontra distribuída de forma equilibrada dentro do território (TOMAZ, 2006). Além do problema de gestão, parte da água do Brasil já não pode ser considerada como recurso natural renovável, devido aos impactos sofridos pela industrialização, agricultura e urbanização, principalmente nas regiões Sul e Sudeste do país, onde a preservação do meio ambiente e da água é pouco estruturada e o desenvolvimento industrial é crescente (BAZARELLA, 2005).

E é com este entendimento que surge a necessidade da aplicabilidade da Política Nacional de Recursos Hídricos, já que este instrumento legal define que a bacia hidrográfica é a unidade territorial para atuação do Sistema Nacional de Recursos Hídricos - SNRH.

Para tanto, é preciso que se entenda com clareza a definição de bacia hidrográfica, e segundo Silveira (2001, p. 23) ela é definida como:

Uma área de captação natural da água da precipitação que faz convergir os escoamentos para um único ponto de saída, seu exutório. É composta basicamente de um conjunto de superfícies vertentes e de uma rede de drenagem formada por cursos d'água que confluem.

No entendimento de Granziera (2003, p. 35), bacia hidrográfica "significa o conjunto constituído por um rio, seus afluentes e mesmo as águas subterrâneas, formando o que se chama de sistema hidrográfico".

Persp. Online: exatas \& eng., Campos dos Goytacazes, 27 (10) 70 - 82 - 2020

seer.perspectivasonline.com.br 
A escolha da bacia hidrográfica como base de unidade de planejamento estabelece limites em áreas que deverão ser adequadas à aplicação da legislação. Isso facilitará ao Poder Público identificar stakeholders, além de beneficiar o gerenciamento destas áreas com a institucionalização de setores específicos.

Para Rebouças (2006), com a definição de limites da bacia como o que determina o perímetro da área planejada, fica mais fácil fazer-se o confronto entre as disponibilidades e as demandas, essenciais para o estabelecimento do balanço hídrico.

De fato, toda a organização da estrutura política dos recursos hídricos no Brasil, mesmo havendo aceitação, não será viável sem que haja participação efetiva do Poder Público, dos usuários e das comunidades, atores envolvidos e interessados diretamente na gestão das águas.

E assim, o Sistema Nacional de Gerenciamento de Recursos Hídricos, impulsionado pela Constituição Federal de 1988, fundamenta-se na articulação da União, dos Estados, Distrito Federal e Municípios na gestão das águas. O que não significa que um município tenha domínio sobre os corpos hídricos. Na verdade, os corpos d'água não identificados como de domínio da União, ou seja, inseridos exclusivamente no território administrativo de um único Estado ou do Distrito Federal são considerados de domínio estadual ou distrital, assim como as águas subterrâneas.

Esse sistema é constituído por órgãos e entidades pertencentes à Administração Pública e por usuários, que têm por finalidade definir os objetivos e composição do Sistema de uma forma integrada, conforme citado nos Artigos 32 e 33 da Lei 9.433/97:

Art. 32. Fica criado o Sistema Nacional de Gerenciamento de Recursos Hídricos, com os seguintes objetivos:

I - coordenar a gestão integrada das águas;

II - arbitrar administrativamente os conflitos relacionados com os recursos hídricos;

III - implementar a Política Nacional de Recursos Hídricos;

IV - planejar, regular e controlar o uso, a preservação e a recuperação dos recursos hídricos;

$\mathrm{V}$ - promover a cobrança pelo uso de recursos hídricos.

Art. 33. Integram o Sistema Nacional de Gerenciamento de Recursos Hídricos:

I - o Conselho Nacional de Recursos Hídricos;

Persp. Online: exatas \& eng., Campos dos Goytacazes, 27 (10) 70 - 82 - 2020 
I-A. - a Agência Nacional de Águas;

II - os Conselhos de Recursos Hídricos dos Estados e do Distrito Federal;

III - os Comitês de Bacia Hidrográfica;

IV - os órgãos dos poderes públicos federal, estaduais, do Distrito Federal e municipais cujas competências se relacionem com a gestão de recursos hídricos;

V - as Agências de Água.

Nessa ótica, entende-se que o sistema foi fundamental para que a nova legislação permitisse o planejamento conjunto e negociação da gestão dos recursos hídricos nas bacias hidrográficas, estabelecendo também as diretrizes complementares para implantação da Política Nacional de Recursos Hídricos (ADAM, 2008).

Ainda com o propósito de estabelecer estrutura para o cumprimento da PNRH, a Lei 9.433 desenvolveu instrumentos para gestão das águas:

Art. $5^{\circ}$ - São instrumentos da Política Nacional de Recursos Hídricos:

I - os Planos de Recursos Hídricos;

II - o enquadramento dos corpos de água em classes, segundo os usos preponderantes da água;

III - a outorga dos direitos de uso de recursos hídricos;

IV - a cobrança pelo uso de recursos hídricos;

V - o Sistema de Informações sobre Recursos Hídricos.

Enquanto instrumentos de gestão, os Planos de Bacia são planos diretores que contextualizam a situação da Bacia e norteiam projetos de longo prazo considerando aspectos diversos como situação dos recursos hídricos, padrões históricos e demográficos de uso e ocupação do solo e estrutura das atividades produtivas. Por essa razão, consubstanciando os Planos de Bacia, são elaborados diagnósticos socioeconômicos que retratam além dos padrões culturais e sociais das comunidades presentes, as formas de uso da água e as demandas hídricas das atividades econômicas da região. O objetivo é sistematizar um conjunto de informações que fundamentem projetos de obras e melhorias, bem como indiquem a disponibilidade qualiquantitativa de recursos hídricos para atender a demanda existente e projetos futuros, priorizando sempre o abastecimento humano e a dessedentação animal, conforme legalmente estabelecido (TEIXEIRA et al., 2016).

O Plano de Recursos de Recursos Hídricos tem como objetivos orientar as decisões de Governo e das instituições que compõem o Sistema Nacional de Gerenciamento dos Recursos Hídricos, propor a implementação de programas nacionais e regionais e promover a harmonização e adequação de políticas públicas para buscar o equilíbrio entre a oferta e a demanda de água, de forma a assegurar as disponibilidades hídricas em quantidade e qualidade para o uso racional e sustentável.

Persp. Online: exatas \& eng., Campos dos Goytacazes, 27 (10) 70 - 82 - 2020

seer.perspectivasonline.com.br 


\section{CONCLUSÕES}

Inicialmente, conclui-se que o Código de Águas foi o marco da Gestão de Recursos Hídricos no País e desenvolveu novos conceitos e procedimentos sobre a água, bem como um novo olhar para o bem natural que acabara por se tornar um recurso. Continuamente destacase no texto a Política Nacional de Recursos Hídricos - PNRH, que, além de ratificar e retificar parte do que foi implementado pelo Código das Águas, inseriu objetivos e instrumentos de gerenciamento para as bacias hidrográficas, além de criar um novo sistema.

Vale ressaltar que a Política Nacional de Meio Ambiente - PNMA foi um importante marco na proteção jurídica do meio ambiente no Brasil, além de congregar leis anteriormente esparsas e agora compiladas num mesmo diploma legal, especificamente sobre recursos naturais que despertam interesse econômico.

Posteriormente têm-se o Código Florestal que, além de garantir e dispor de vasta normatização sobre a proteção dos recursos naturais, estabelece regras sobre as áreas de proteção permanente, assunto de maior relevância e interesse para esta pesquisa. Inserido ainda neste contexto está o Plano Nacional de Saneamento Básico - PLANSAB, que estabelece diretrizes nacionais para o saneamento básico. Vale destacar que, de acordo com o PLANSAB, os recursos hídricos não integram os serviços públicos de saneamento básico, ficando sob a tutela da PNRH. Entretanto, considerou-se necessário caracterizar na pesquisa ações como abastecimento de água, coleta de esgoto e resíduos sólidos, bem como informações sobre a drenagem de águas pluviais urbanas, para entender como o PLANSAB pode contribuir com a PNRH na elaboração e cumprimento de suas propostas.

No Brasil, existe um emaranhado de leis e normas aplicáveis à gestão dos recursos hídricos. Tais aspectos jurídicos, se aplicados de forma coesa e coletiva, podem contribuir com a gestão, melhor distribuição e manutenção da água em quantidade e qualidade disponíveis para todos os usuários.

\section{REFERÊNCIAS}

ADAM, J. I. Gestão de recursos hídricos numa perspectiva de sustentabilidade: uma proposta. 2008. 216 p. Tese (Doutorado), Universidade Federal de Santa Catarina. Programa de Pós-Graduação em Engenharia de Produção, Florianópolis, 2008.

ANA, Agência Nacional de Águas. Manual de procedimentos técnicos e administrativos de outorga de direito de uso de recursos hídricos da agência nacional de águas. Brasília, 2013.

ANA, Agência Nacional de Águas. Disponível em: <http://www2.ana.gov.br/Paginas/servicos/cobrancaearrecadacao/cobrancaearrecadacao.aspx \# >. Acesso em: mar. 2018.

BAZZARELLA, B. B. Caracterização e aproveitamento de água cinza para uso não potável em edificações. 2005. 159 p. Dissertação (Mestrado), Universidade Federal do Espírito Santo. Programa de Pós-Graduação em Engenharia Ambiental, Vitória, Dez. 2005.

BRAGA, Benedito. Água, direito humano. O Estado de São Paulo, p. A2, São Paulo, 21.04.2009.

BRASIL, 1934. Código de Águas. Decreto 24.643.

Persp. Online: exatas \& eng., Campos dos Goytacazes, 27 (10) 70 - 82 - 2020

seer.perspectivasonline.com.br 
BRASIL,1988. Constituição da República Federativa do Brasil. Disponível em:<https://www.presidencia.gov.br>. Acesso em: mar. 2018.

BRASIL, 1981. Política Nacional do Meio Ambiental. Dispõe sobre a Política Nacional do Meio Ambiente, seus fins e mecanismos de formulação e aplicação, e dá outras providências.

BRASIL, 1997. Política Nacional de Recursos Hídricos. Disponível em:< http://www.planalto.gov.br/ccivil_03/leis/19433.htm>. Acesso em: fev. 2018.

BRASIL, 2001. Estatuto da Cidade. Regulamenta os arts. 182 e 183 da Constituição Federal, estabelece diretrizes gerais da política urbana e dá outras providências.

BRASIL, 2007. Lei n. 11.445 de 05 de janeiro de. Estabelece as diretrizes nacionais para o saneamento básico. Brasília: Diário Oficial da União, Seção 1, p. 3-7.

BRASIL, 2012. Lei 12.651. Código Florestal. Dispõe sobre a proteção da vegetação nativa; altera as Leis $\mathrm{n}^{\mathrm{os}}$ 6.938, de 31 de agosto de 1981, 9.393, de 19 de dezembro de 1996, e 11.428, de 22 de dezembro de 2006; revoga as Leis $\mathrm{n}^{\text {os }} 4.771$, de 15 de setembro de 1965, e 7.754, de 14 de abril de 1989, e a Medida Provisória no 2.166-67, de 24 de agosto de 2001; e dá outras providências.

CAPONERA, D. A. Princípios do direito e administração das águas nacionais e internacionais. Coordenador da Edição Brasileira Marcos A. V. de Freitas e Arnaldo A. Setti; $2^{\text {a }}$ Ed. Rio de Janeiro. Editora Synergia: IVIG/COPPE/UFRJ, 2012.

GRANZERA, M. L. M. Direito de Águas: disciplina jurídica das águas doces. 3 ed. São Paulo: Atlas, 2006.

LEMOS, H. M. de; SALATI, E. Água e o Desenvolvimento sustentável. Águas Doces do Brasil: capital ecológico, uso e conservação. São Paulo: Editora Escrituras, 2003.

LIMA, T. C. S.; MIOTO, R. C. T. Procedimentos metodológicos na construção do conhecimento científico: a pesquisa bibliográfica. Revista Katálysis, v. 10, n. SPE, p. 37-45, 2007. DOI: 10.1590/S1414-49802007000300004

LIMA, J. G. O paradoxo da água. Veja São Paulo, ano 38, $\mathrm{n}^{\circ}$ 41, 12 de Outubro de 2005. Parte integrante da edição 1926. p 89 - $92 . \quad$ Disponível em: $\langle$ http://www.veja.abril.com.br/acervodigital/home.aspx $>$. Acesso em mar. 2018.

MEZZAROBA, O.; MONTEIRO, C. S. Manual de metodologia da pesquisa no direito. $6^{\mathrm{a}}$ Edição. São Paulo: Saraiva, 2014.

Organização das Nações Unidas - ONU. A ONU e a Água. Disponível em: <http://onu.org.br/a-onu-em-acao/a-onu-e-a-agua/>. Acesso em: mar. 2018.

PAVAN, F. S.; SANTOS, A. S. P.; TEIXEIRA, T.; PERTEL, M. V. ACSERALD, M.; MARCONDES, Q.; HILDEBRANDT, D. Aplicação do método de valoração contingente para mensurar a percepção sócio ambiental dos moradores que vivem no entorno da Lagoa do Vigário. Revista Perspectivas Online: Humanas e Sociais Aplicadas. v. 6, n. 15. P. 31-52, 2016. DOI: $10.25242 / 88766152016971$

Persp. Online: exatas \& eng., Campos dos Goytacazes, 27 (10) 70 - 82 - 2020 seer.perspectivasonline.com.br 
POMPEU, C. T. Direito de Águas no Brasil. $2^{\circ}$ ed. São Paulo: Editora Revista dos Tribunais, 2010.

PETRELlA, R. O Manifesto da Água: Argumentos para um contrato mundial. Petrópolis RJ: Vozes, 2002. 159 p.

REBOUÇAS, A. C. Proteção dos recursos hídricos. In: BENJAMIN HERMAN, Antônio. Direito, água e vida: law, water and the web of life. vol 1. São Paulo: Imprensa Oficial do Estado de São Paulo: 2003. p. 252.

SÉGUIN, E. Direito ambiental: nossa casa planetária. Rio de Janeiro: Forense, 2002.

TEIXEIRA T.; SOUZA, F. P.; PERTEL, M.; ACSELRAD, M.; PEREIRA, A. S. Diagnóstico socioeconômico em bacias hidrográficas: bacia do Rio das Contas. Perspectivas Online: Exatas \& Engenharias, v. 6, p. 15-28, 2016. Disponível em: https://ojs3.perspectivasonline.com.br/exatas_e_engenharia/article/view/961 Acesso em: Fev. 2020. DOI: $10.25242 / 885 X 6142016961$

TOMAZ, P. A água doce no mundo. 2006. Disponível em: $<$ http://www.aceguarulhos.com.br/content.php?m=20060322001006. Acesso em: mar. 2018.

ZILBERMAN, I. Introdução à Engenharia Ambiental. $1^{\text {o }}$ Ed. Canoas: Ulbra, 2004. 57 p. 